\title{
Comparação entre os poluentes atmosféricos emitidos por uma caldeira flamotubular movida a gás natural e a óleo combustível BPF 2A
}

Comparison between atmospheric pollutants emitted by a fire-tubular boiler fueled by natural gas and fuel oil number $2 \mathrm{~A}$

Comparaison entre les polluants atmosphériques émis par une chaudière tubulaire qui fonctionne au gaz naturel et l'huile combustible BPE $2 A$

Comparación de los contaminantes atmosféricos emitidos por una caldera flamotubular alimentada por gas natural y aceite combustible BPF $2 \mathrm{~A}$

\section{Lenice Carrilho de Oliveira Moreira*}

Recebido em 19/9/2011 revisado e aprovado em 17/11/2011; aceito em 21/12/2011

\begin{abstract}
Resumo: Este trabalho baseia-se na pesquisa realizada para identificação dos poluentes atmosféricos emitidos por uma caldeira flamotubular movida a gás natural e suas concentrações. Ao comparar os dados obtidos com os resultados apresentados, quando a caldeira era movida a óleo combustível, e com a legislação em vigor, verificou-se que a troca do combustível proporcionou uma redução significativa na concentração dos poluentes medidos, melhorando a qualidade do ar e, consequentemente, a qualidade de vida das pessoas que vivem nas suas proximidades. Palavras-chave: Poluição ambiental. Caldeira. Gás natural.

Abstract: This paper is based on research carried out with the aim of identifying and quantifying the concentrations of the atmospheric pollutants emitted by a fire-tubular boiler fuelled by natural gas. By comparing the obtained data with results presented when the boiler used fuel oil and with the legislation in vigor, it was verified that the changing of the fuel type led to a significant reduction in the concentration of the measured pollutants, improving air quality and consequently the quality of life of people living nearby.

Key words: Environmental pollution. Boiler. Natural gas.

Résumé: Ce travail est basé sur la recherche réalisée pour identifier les polluants atmosphériques émis par une chaudière tubulaire qui fonctionne au gaz naturel et ses concentrations. Après comparaison des données obtenues avec les résultats présentés quand la chaudière fonctionnait à l'huile combustible, et avec la législation courante, il a été établi que l'échange du combustible a fourni une réduction significative dans la concentration des polluants mesurés, ce qui a amélioré la qualité de l'air et, en conséquence, la qualité de vie des personnes qui vivent dans sa proximité.

Mots-clés: Pollution de l'environnement. Chaudière. Le gaz naturel.

Resumen: Este artículo se basa en investigaciones llevadas a cabo para identificar los contaminantes atmosféricos emitidos por una caldera flamotubular alimentada por gas natural y sus concentraciones. Al comparar los datos con los resultados que se presentan cuando la caldera fue accionada por aceite combustible y con la legislación, se encontró que el cambio de combustible proporcionó una reducción significativa en la concentración medida de los contaminantes, la mejora de la calidad del aire y por lo tanto la calidad de vida de las personas que viven cerca.

Palabras clave: Contaminación del medio ambiente. Caldera. Gas natural.
\end{abstract}

\section{Introdução}

A sobrevivência da vida na Terra e, consequentemente, da própria humanidade, vem sendo exposta a perigos devido às mudanças promovidas, em grande parte, pela ação direta do homem sobre o meio ambiente, resultante do crescimento populacional, da urbanização descontrolada, de atividades agrícolas, da geração e consumo de energia, de processos industriais poluentes, entre outros. Somado a isso se evidencia a rapidez e amplitude desse desenvolvimento, com efeitos cumulativos, e a ultrapassagem de certos limites que o padrão de consumo da civilização acarreta.

Assim, o ser humano começou a perceber que a preservação ambiental deve ser perseguida, buscando-se uma redução eficiente dos processos de degradação dos recursos naturais.

A queima de combustíveis fósseis é a principal fonte de poluição atmosférica, sendo que, para que ocorra diminuição na quantidade de emissão desses poluentes, as alternativas são os usos das chamadas fontes limpas - energia solar, eólica e das marés, por exemplo. Destaca-se, também, que o gás

\footnotetext{
* Administradora. Mestre em Tecnologias ambientais pela Fundação Universidade Federal de Mato Grosso do Sul. E-mail: lenice.moreira@ufms.br
} 
natural, embora seja um combustível fóssil, já ocupa o lugar de fonte energética abundante menos nociva ao meio ambiente da atualidade.

Apesar de não ser um estado predominantemente industrial, o meio ambiente tem se tornado foco de interesse da sociedade sul-mato-grossense, em especial a de Campo Grande, haja vista que o uso sustentável dos recursos passou a ser uma questão de sobrevivência da espécie humana.

Vale esclarecer que esse combustível tornou-se uma realidade em Mato Grosso do Sul desde a implantação do Gasoduto BolíviaBrasil, em operação desde 1999, surgindo como uma nova fonte de energia, que passou a ser empregada, também, nos processos de geração de vapor, nos quais utilizavam-se, anteriormente, combustíveis líquidos, com destaque para o óleo BPF (baixo poder de fluidez), e sólidos, como lenha e bagaço de cana.

A Universidade Federal de Mato Grosso do Sul (UFMS), assim como a maioria das indústrias de Campo Grande, utilizava, na caldeira geradora de vapor, localizada no Núcleo de Hospital Universitário (NHU), o combustível óleo BPF 2A. Contudo, consciente da necessidade de contribuir para a melhoria das condições atmosféricas da região e considerando a disponibilização, por meio da Companhia de Gás do Estado de Mato Grosso do Sul (MSGÁS), de uma rede de distribuição dentro de seus limites territoriais, levando o gás até próximo à caldeira, o NHU passou a utilizar o gás natural como combustível.

Diante disso, este estudo estabeleceu, como finalidade, identificar os poluentes atmosféricos oriundos da caldeira do NHU movida a gás natural e suas concentrações; promover uma comparação desses resultados com os obtidos por Okano (2004), quando do desenvolvimento de estudos, com a mesma caldeira, porém movida a óleo BPF 2A, e, ainda, com a legislação vigente.

Para tanto, trabalhou-se especificamente com a caldeira tipo flamotubular instalada no NHU/UFMS, utilizada para gerar vapor d'água saturado, a ser consumido na lavanderia, na nutrição (cozinha), na esterilização/ limpeza de equipamentos cirúrgicos (autoclave), e no aquecimento de água para uso geral.

\section{Poluição atmosférica}

Todas as mudanças nas características físico-químicas ou biológicas do ar, da água ou do solo, que afetam negativamente a saúde, a sobrevivência ou as atividades humanas e de outros organismos vivos, são, segundo Lora e Teixeira (2001), consideradas poluição.

A Resolução CONAMA n. 003, de 28/6/1990, define, como poluente atmosférico, qualquer forma de matéria ou energia com intensidade e em quantidade, concentração, tempo ou características em desacordo com os níveis estabelecidos, e que tornem ou possam tornar o ar: I - impróprio, nocivo ou ofensivo à saúde; II - inconveniente ao bem-estar público; III - danoso aos materiais, à fauna e à flora; IV - prejudicial à segurança, ao uso e gozo da propriedade e às atividades normais da comunidade.

É válido afirmar que os poluentes do ar originam-se principalmente da combustão incompleta de combustíveis fósseis, para fins de transporte, aquecimento e produção industrial.

A poluição do ar, de acordo com Mota (2000), pode originar-se de fontes naturais (vulcões; florestas (queimadas); decomposição anaeróbia de matéria orgânica; desnitrificação por bactérias) e, antrópicas (indústrias; meios de transporte; destruição e queima da vegetação; queima de combustível; queima do lixo; aplicação de agrotóxicos; fermentação de resíduos (dejetos, lixo); uso de "sprays", refrigeração, fabricação de espumas plásticas, solventes; compostos radioativos.

Os processos industriais respondem pela emissão de material particulado e por vários gases poluentes, tais como, os óxidos de enxofre $\left(\mathrm{SO}_{2}\right)$, os óxidos de nitrogênio (NO e $\left.\mathrm{NO}_{2}\right)$; gás sulfídrico $\left(\mathrm{H}_{2} \mathrm{~S}\right)$; hidrocarbonetos, ácido clorídrico $(\mathrm{HCl})$, entre outros. As fontes móveis de poluição (veículos, aviões, barcos, locomotivas) colaboram para o lançamento de material particulado, monóxido de carbono (CO), óxidos de nitrogênio $\left(\mathrm{NO}_{\mathrm{X}}\right)$, óxido de enxofre $\left(\mathrm{SO}_{2}\right)$, hidrocarbonetos e aldeídos.

A poluição atmosférica pode resultar em impactos locais, regionais e globais, tais como: danos à saúde humana, efeitos sobre a flora e a fauna, chuvas ácidas, efeito estufa, destruição da camada de ozônio.

A concentração de um poluente atmosférico, em determinada área receptora, 
depende do tipo de fonte e da concentração com que foi lançado, bem como das condições de dispersão desse poluente na atmosfera.

A Resolução CONAMA n. 005, de 15/6/1989, que instituiu o Programa Nacional de Controle da Qualidade do Ar (PRONAR), definiu, como limite máximo de emissão, a quantidade de poluentes permissível de ser lançada por fontes poluidoras na atmosfera, sendo que esses limites serão diferenciados em função da classificação de usos pretendidos para as diversas áreas. Os padrões de qualidade do ar foram estabelecidos por meio da Resolução CONAMA n. 003, de 28/6/1990.

A Resolução CONAMA n. 382, de 26/12/2006, estabelece os limites máximos de emissão de poluentes atmosféricos para fontes fixas, ou seja, a quantidade máxima de poluentes permissível de ser lançada para a atmosfera.

\section{Caldeiras geradoras de vapor e o gás natural}

Segundo Arruda (1977), uma forma rudimentar de turbina a vapor já existia desde 130 a.C., criada por Heron de Alexandria, a qual viria provocar, séculos mais tarde, uma verdadeira revolução industrial, com a invenção da máquina a vapor.

As caldeiras, hoje, são utilizadas em larga escala em várias etapas de processos industriais que necessitam de calor ou energia de pressão, tais como indústrias de alimentos, frigoríficos e hospitais, sendo também utilizadas em sistemas de cogeração, nos quais se produz vapor para uso em processos produtivos, aproveitando-se o excedente para geração de eletricidade.

As caldeiras podem ser classificadas de acordo com as classes de pressão, o grau de automatização, os tipos de energia empregada e o tipo de troca térmica.

Dentre os combustíveis mais utilizados, destacam-se a lenha, o carvão, o bagaço de cana, o óleo BPF, o óleo diesel, o gás natural e o GLP (gás liquefeito de petróleo). Quanto à troca térmica, classificam-se em: flamotubulares, aquotubulares, mistas e elétricas.

Segundo Torreira (1995), as caldeiras flamotubulares são aquelas em que os gases provenientes da combustão (gases quentes) circulam no interior dos tubos, ficando por fora a água.
O vapor é gerado pelo calor transferido dos gases quentes da combustão, através das paredes metálicas dos tubos, para a água que os circunda; à medida que os gases fluem através dos tubos, eles são resfriados pela transferência de calor para a água.

Convém frisar que a qualidade da água de uma caldeira é condição fundamental de segurança e durabilidade, pois incrustações nas paredes internas dos tubos de vaporização atuam como uma camada isolante, o que aumenta o consumo de combustível e provoca o enfraquecimento desses tubos.

Por se tratar de um combustível gasoso, a utilização do gás natural requer uma série de cuidados e acessórios para garantir uma operação segura. A NBR 12313 trata do Sistema de Combustão, Controle e Segurança para Utilização de Gases Combustíveis em Processos de Baixa e Alta Temperatura.

O gás natural, portanto, é um combustível fóssil, resultante da decomposição de matéria orgânica (vegetal e animal) em meio carente de oxigênio e sob condições elevadas de pressão e temperatura. Mais leve que o ar, ele está entre os energéticos com menor potencialidade de impactar o meio ambiente. Seu estado natural gasoso e sua baixa densidade proporcionam rápida dissipação na atmosfera e, para que se inflame, é preciso que seja submetido à temperatura superior a $620^{\circ} \mathrm{C}$. Como sua combustão se processa de forma mais completa, é baixíssima a emissão de CO. Além disso, é incolor e inodoro, sendo, por questões de segurança, odorizado com enxofre. Sua inalação acidental não provoca danos à saúde, vez que suas substâncias componentes são inertes no corpo humano.

As principais utilizações do gás natural têm sido como combustível industrial, comercial, domiciliar e residencial, sendo também utilizado como matéria-prima nas indústrias petroquímica e de fertilizantes.

O gás natural pode ser transportado na forma gasosa ou liquefeito, sendo que, para grandes volumes e em regime de operação contínua, o ideal é utilizar-se de gasodutos.

Esse gás chega ao estado de Mato Grosso do Sul através do gasoduto Bolívia-Brasil, que tem $3.150 \mathrm{~km}$ de extensão, sendo 2.583 $\mathrm{km}$ situados em solo brasileiro e $567 \mathrm{~km}$ em solo boliviano. O empreendimento liga Rio Grande, na Bolívia, a Porto Alegre/RS, 
passando pelos estados de Mato Grosso do Sul, São Paulo, Paraná e Santa Catarina. Em seu ramal tronco, no Estado de Mato Grosso do Sul, a extensão do gasoduto é de $716 \mathrm{~km}$, ligando os municípios de Corumbá e Três Lagoas, passando por Campo Grande.

Apesar de o gasoduto Bolívia-Brasil ter trazido para o Estado a possibilidade de substituição dos combustíveis líquidos e sólidos pelo gás natural, ainda é muito tímido o uso desse combustível pela indústria para geração de energia (calor), estando, entretanto, bastante desenvolvido o uso veicular.

É importante ressaltar que o gás natural deverá desempenhar (ou já vem desempenhando) papel expressivo na sociedade mundial, permitindo a estruturação de uma civilização tecnológica e economicamente desenvolvida, ambiental e ecologicamente sustentável, atendendo à demanda energética industrial, comercial e residencial eà demanda de insumos da moderna indústria química e de materiais.

\section{Materiais e métodos}

O estudo foi desenvolvido nas dependências do Núcleo de Hospital Universitário (NHU), da Universidade Federal de Mato Grosso do Sul, em Campo Grande, MS, que utiliza uma caldeira geradora de vapor, tipo flamotubular, com retorno de chama, semiautomática, marca ATA, modelo H-3-14, fabricada em 1983.

Até julho de 2005, a referida caldeira utilizava o óleo BPF 2A, quando foi convertida a gás natural, passando a operar definitivamente com esse combustível a partir de dezembro/ 05 .

O vapor gerado pela caldeira é utilizado na lavanderia (70\% da produção); na nutrição ( $20 \%$ da produção); e para aquecimento e esterilização ( $10 \%$ da produção).

As concentrações dos gases emitidos na combustão pela caldeira a gás natural, do NHU, foram mensuradas por meio do Analisador de Poluentes Atmosféricos da marca Testo, modelo 350 XL de fabricação alemã, composto de dois equipamentos em um, Testo 350 XL e Testo 454, que, juntos, constituem um instrumento de medição para medidas sensíveis em um processo térmico complexo.

A Unidade de Controle (Testo 454) é um instrumento portátil de medição, em que pode ser acoplada uma ampla categoria de sondas, as quais permitem medir, com precisão, temperatura, umidade, velocidade, turbulência, pressão, rpm, corrente e voltagem.

A Caixa Analisadora, Testo $350 \mathrm{XL}$, mede todos os parâmetros de um processo de combustão $\left(\mathrm{O}_{2}, \mathrm{CO}, \mathrm{CO}_{2}, \mathrm{NO}, \mathrm{NO}_{2}, \mathrm{NO}_{\mathrm{x}}\right)$, dependendo dos componentes acoplados (inclusive do tipo de célula adquirida).

Importante destacar que a identificação da concentração dos poluentes atmosféricos gerados pela caldeira do NHU foi realizada no período de fevereiro a junho do ano de 2007.

Para que os resultados identificados por Okano (2004), quando a caldeira era movida a óleo combustível BPF 2A, pudessem ser comparados com os resultados deste estudo, as medições foram realizadas nos mesmos locais e distâncias promovidas, ou seja, no interior da chaminé da caldeira (no centro, a $5 \mathrm{~cm}$ do centro, a $10 \mathrm{~cm}$ do centro e, a $15 \mathrm{~cm}$ do centro); na base da chaminé; e a $10 \mathrm{~m}$ da base da chaminé.

A chaminé da caldeira, confeccionada em chapa de $6,0 \mathrm{~mm}$, com diâmetro de 40 $\mathrm{cm}$, mede $3,5 \mathrm{~m}$ de altura e possui proteção contrachuva no topo (chapéu chinês). O tubo, acoplado à caldeira, atravessa a parede da casa de caldeiras, na horizontal, a uma altura de 2,50m do piso acabado, saindo para o ambiente na vertical, sendo os gases de exaustão liberados a uma altura de $6 \mathrm{~m}$ do solo.

Para coleta dos poluentes atmosféricos dentro da chaminé, fez-se nesta um orifício de cerca de $10 \mathrm{~mm}$ de diâmetro, logo acima da curva de saída na vertical, a uma altura de 3,30m do piso acabado. Para medir a concentração dos gases na base da chaminé, e a $10 \mathrm{~m}$ da chaminé, utilizou-se o mesmo equipamento (Testo $350 \mathrm{XL}$ ), com a sonda posicionada a $1,50 \mathrm{~m}$ de altura do solo.

Diferentemente de Okano (2004), que coletou os dados apenas nos fundos da casa de caldeiras, neste estudo, a concentração dos gases, a 10m da chaminé, foi coletada nos quatro quadrantes (norte, sul, leste e oeste), a partir da localização dela. Os resultados apresentados, tanto dentro da chaminé, quanto na base e a $10 \mathrm{~m}$ da chaminé, correspondem à média aritmética dos valores medidos.

Para avaliação dos poluentes atmosféricos, foram realizadas trinta medições, 
sendo 16 no período matutino e 14 no período vespertino (no interior da chaminé, na base da chaminé e a $10 \mathrm{~m}$ da base da chaminé).

\section{Resultados obtidos}

As concentrações dos poluentes atmosféricos emitidos pela caldeira, enquanto operando a gás natural, foram avaliadas e, após, comparadas com as concentrações dos poluentes atmosféricos lançados pela caldeira, quando operada a óleo combustível, e com a legislação vigente.

Os resultados correspondentes aos níveis de concentração dos poluentes encontrados no interior da chaminé da caldeira, bem como os dados da literatura/legislação, estão demonstrados na Tabela 1.

Tabela 1 - Concentração de poluentes no interior da chaminé da caldeira

\begin{tabular}{|c|c|c|c|}
\hline $\begin{array}{l}\text { Elementos } \\
\text { analisados }\end{array}$ & Gás natural & Óleo combustível ${ }^{\mathrm{a}}$ & Literatura/Legislação \\
\hline $\mathrm{CO}(\mathrm{ppm})$ & 1,8 & 46,2 & $0,12^{\mathrm{b}} ; 0,1^{\mathrm{c}} ; 9^{\mathrm{d}}(8 \mathrm{~h}), 35^{\mathrm{d}}(1 \mathrm{~h}) ; 9^{\mathrm{f}}(8 \mathrm{~h}), 35^{\mathrm{f}}(1 \mathrm{~h}) ; 0-9,0^{\mathrm{g}}$. \\
\hline $\mathrm{CO}_{2}(\%)$ & 5,7 & 6,9 & $0,03^{c}$. \\
\hline NO (ppm) & 22,5 & 310,2 & $0,00001-0,00005^{\mathrm{b}} ;<0,002^{\mathrm{c}}$. \\
\hline $\mathrm{NO}_{2}(\mathrm{ppm})$ & 0,1 & 0,3 & $0,0001-0,0005^{\mathrm{b}} ;<0,002^{\mathrm{c}} ; 0,053^{\mathrm{d}}(\mathrm{maa})^{*} ; 0,2^{\mathrm{f}} ; 0-0,2^{\mathrm{g}}$. \\
\hline $\mathrm{NO}_{\mathrm{x}}(\mathrm{ppm})$ & 22,6 & 310,5 & $154^{\mathrm{e}}$ (gás); $156^{\mathrm{h}}$ (gás); 370e (óleo); $779^{\mathrm{h}}$ (óleo). \\
\hline
\end{tabular}

Obs: * Média aritmética anual.

Fonte: ${ }^{\mathrm{a}}$ Okano (2004); ${ }^{\mathrm{b}}$ Lora \& Teixeira (2001); ${ }^{\mathrm{c}} \operatorname{Mota}(2000) ;{ }^{\mathrm{d}}$ USEPA (2010); ${ }^{\mathrm{e}}$ World Bank (1998); ${ }^{\mathrm{f}}$ Res. CONAMA n. 003/90; ${ }^{g}$ CETESB (2010); ${ }^{\text {h }}$ Res. CONAMA n. 382/06.

Analisando os resultados obtidos no interior da chaminé, com a caldeira operando a gás natural, verifica-se que, segundo Lora e Teixeira (2001) e Mota (2000), as concentrações de $\mathrm{CO}, \mathrm{CO}_{2}, \mathrm{NO}$ e $\mathrm{NO}_{2}$, estão acima dos limites estabelecidos, caracterizando o ar como poluído ou contaminado. Considerando a Agência de Proteção Ambiental dos Estados Unidos (USEPA) (2010), a concentração de CO está em conformidade com a legislação, entretanto a concentração de $\mathrm{NO}_{2}$ está acima do limite estabelecido por aquela Agência. De acordo com a Resolução CONAMA n. 003/90, tanto a concentração de $\mathrm{CO}$, quanto a concentração de $\mathrm{NO}_{2}$ estão em conformidade com os padrões estabelecidos. Comparando-se os resultados encontrados para $\mathrm{CO}$ e $\mathrm{NO}_{2}$, com os valores estabelecidos pela CETESB (2010), para o estado de São Paulo, verifica-se que a qualidade do ar é considerada de boa a regular, atendendo ao padrão CONAMA.

Segundo a Resolução CONAMA n. 382/06, que fixa o valor limite de $\mathrm{NO}_{\mathrm{x}}$ (como $\mathrm{NO}_{2}$ ), para processos de geração de calor a partir da combustão externa de gás natural, com potência térmica nominal menor que 70 MW e o Banco de Dados Americano (World
Bank) (1998), que limita o valor máximo de $\mathrm{NO}_{x}$ lançado por usinas termelétricas convencionais a gás natural, a média dos níveis de concentração de $\mathrm{NO}_{\mathrm{X}}$ lançada pela chaminé está abaixo do permitido pelas legislações nacional e americana.

Os aumentos na concentração de $\mathrm{NO}_{x}$ são vinculados ao acréscimo de temperatura na queima do combustível, porém, a temperatura medida na chaminé apresentou valores abaixo do normal (deveria estar acima de $200^{\circ} \mathrm{C}$, sendo considerada normal, temperatura de até $240^{\circ} \mathrm{C}$ ). Durante as medições, por várias vezes, a válvula de segurança foi acionada, em virtude, não do aumento da pressão, o que ocorre quando ela atinge entre 9,0 e 9,5 kgf.cm ${ }^{-2}$, mas, sim, em virtude da temperatura. Nessa ocasião, a caldeira estava funcionando em estado precário, apresentando grande quantidade de vazamentos, entre outros problemas, não refletindo, assim, a temperatura medida na chaminé, a temperatura efetiva existente dentro da caldeira. Conforme relato dos operadores da caldeira, por ocasião do acionamento da válvula de segurança, a temperatura, medida no termômetro acoplado à caldeira, variava entre $300^{\circ} \mathrm{C}$ e $310^{\circ} \mathrm{C}$. 
Nota-se, como era de se esperar, quando da comparação entre a combustão a óleo combustível e a gás natural, que todos os gases de combustão $\left(\mathrm{CO}, \mathrm{CO}_{2}, \mathrm{NO}, \mathrm{NO}_{2}\right.$ e $\left.\mathrm{NO}_{x}\right)$, sofreram redução.

Comparando-se os resultados obtidos por Okano (2004) com os deste estudo, verifica-se que a concentração de $\mathrm{CO}$ medida no interior da chaminé, considerada imprópria segundo a Resolução CONAMA n. 003/90 e a USEPA (2010), teve uma redução de 96,10\%, passando de 46,2 ppm para 1,8 ppm.

Segundo Okano (2004), a grande variação nos resultados obtidos em seu estudo deve-se, provavelmente, à queima não uniforme do combustível, em virtude da não padronização da mistura ar-combustível, que era realizada de forma diferente por cada um dos cinco operadores da caldeira, além da variação no consumo de vapor solicitado no hospital, por ocasião da medição.

A concentração de $\mathrm{CO}_{2}$ passou de $6,9 \%$ para $5,7 \%$, apresentando uma redução de $17,39 \%$ com o uso do gás natural. Segundo Berman (2002), com a utilização de gás natural em substituição ao óleo combustível, ocorre uma redução de, aproximadamente, $32 \%$ na concentração de CO2.

A concentração de NO medida no interior da chaminé, com o uso do gás natural, passou de 310,2 ppm para 22,5 ppm, corres- pondendo a uma redução de $92,75 \%$.

A concentração de $\mathrm{NO} 2$ no interior da chaminé sofreu uma redução de $66,67 \%$ com o uso do gás natural, passando de 0,3 ppm para 0,1 ppm. Quando do uso de óleo combustível, a concentração emitida encontrava-se acima da permitida pela Resolução CONAMA n. 003/90 e, segundo a CETESB (2010), o ar era classificado como inadequado, não atendendo ao padrão CONAMA.

A concentração de NOx, lançada pela chaminé da caldeira, diminuiu $92,72 \%$ com o uso do gás natural, passando de 310,5 ppm para 22,6 ppm. De acordo com a Resolução CONAMA n. 382/06, que fixa o valor limite de $\mathrm{NO}_{\mathrm{X}}$ (como $\mathrm{NO}_{2}$ ), para processos de geração de calor a partir da combustão externa de óleo combustível, com potência térmica nominal menor que $10 \mathrm{MW}$, e o Banco de Dados Americano World Bank (1998), que limita o valor máximo de $\mathrm{NO}_{\mathrm{x}}$, lançado por usinas termelétricas convencionais a óleo combustível, o valor obtido por Okano (2004) também estava abaixo do permitido pelas duas legislações.

Na Tabela 2, são demonstrados os resultados relativos aos níveis de concentração dos poluentes encontrados na base da chaminé da caldeira, bem como os dados da literatura/ legislação.

Tabela 2 - Concentração de poluentes na base da chaminé da caldeira

\begin{tabular}{|c|c|c|c|}
\hline $\begin{array}{l}\text { Elementos } \\
\text { analisados }\end{array}$ & Gás natural & Óleo combustível ${ }^{\mathrm{a}}$ & Literatura/Legislação \\
\hline $\mathrm{CO}(\mathrm{ppm})$ & 0,1 & 0,1 & $0,12^{\mathrm{b}} ; 0,1^{\mathrm{c}} ; 9^{\mathrm{d}}(8 \mathrm{~h}), 35^{\mathrm{d}}(1 \mathrm{~h}) ; 9^{\mathrm{f}}(8 \mathrm{~h}), 35^{\mathrm{f}}(1 \mathrm{~h}) ; 0-9,0^{\mathrm{g}}$ \\
\hline $\mathrm{NO}(\mathrm{ppm})$ & 0,1 & 14,8 & $0,00001-0,00005^{\mathrm{b}} ;<0,002^{\mathrm{c}}$ \\
\hline $\mathrm{NO}_{2}(\mathrm{ppm})$ & 0,1 & - & $0,0001-0,0005^{\mathrm{b}} ;<0,002^{\mathrm{c}} ; 0,053^{\mathrm{d}}(\mathrm{maa})^{*} ; 0,2^{\mathrm{f}} ; 0-0,2^{\mathrm{g}}$. \\
\hline $\mathrm{NO}_{\mathrm{x}}(\mathrm{ppm})$ & 0,1 & - & 154 (gás); 156 (gás); 370 (óleo); $779^{\mathrm{h}}$ (óleo). \\
\hline
\end{tabular}

Obs: 1) A emissão de $\mathrm{CO}_{2}$ e o ponto de orvalho não foram detectados pelo Analisador Testo $350 \mathrm{XL}$;

2)* Média aritmética anual.

Fonte: ${ }^{\mathrm{a}}$ Okano (2004); ${ }^{\mathrm{b}}$ Lora \& Teixeira (2001); ${ }^{\mathrm{c}}$ Mota (2000); ${ }^{\mathrm{d}}$ USEPA(2010); ${ }^{\mathrm{e}}$ World Bank (1998); ${ }^{\mathrm{f}}$ Res. CONAMA n. 003/90; ${ }^{\mathrm{g}}$ CETESB (2010); ${ }^{\mathrm{h}}$ Res. CONAMA n. 382/06.

Analisando os resultados obtidos na base da chaminé com a caldeira operando a gás natural, nota-se que a concentração de $\mathrm{CO}$ classifica o ar como limpo e de boa qualidade, de acordo com Lora e Teixeira (2001), Mota (2000) e CETESB (2010), estando também em conformidade com os valores estipulados pela
Resolução CONAMA 003/90 e pela USEPA (2010).

A concentração obtida para $\mathrm{NO}_{2}$ classifica o ar como contaminado segundo Lora e Teixeira (2001), Mota (2000) e USEPA (2010), atendendo, entretanto, aos padrões estabelecidos pela Resolução CONAMA n. 003/90 e pela 
CETESB (2010). A concentração de $\mathrm{NO}_{x}$ atende plenamente ao estabelecido na legislação.

Comparando-se as concentrações de poluentes atmosféricos emitidos pela caldeira operando a gás natural e a óleo BPF 2A, verificou-se que o elemento que apresentou variação mais significativa foi o $\mathrm{NO}$, cuja média passou de 14,8 ppm para 0,1 ppm, correspondendo a uma redução de 99,32\%. Ainda assim, a concentração de NO classifica o ar como poluído segundo Lora e Teixeira (2001) e Mota (2000), sendo nocivo à saúde e ao bem-estar do homem.

Nota-se que as concentrações de $\mathrm{NO}$ medidas no interior da chaminé e na base da chaminé (Tabelas 1 e 2), com a caldeira ope- rando tanto a óleo combustível quanto a gás natural, apresentam um percentual de redução semelhante - de 310,2 ppm para 14,8 ppm e, de $22,5 \mathrm{ppm}$ para $0,1 \mathrm{ppm}(95,2 \%$ e $99,5 \%$, respectivamente), demonstrando uma diminuição significativa já na base da chaminé.

Não foi detectada, pelo Analisador de Poluentes Atmosféricos Testo 350 XL, a concentração de $\mathrm{NO}_{2}$ e $\mathrm{NO}_{\mathrm{X}}$ nas medições realizadas na base da chaminé quando ela operava com combustão a óleo combustível.

Os resultados correspondentes aos níveis de concentrações dos poluentes lançados a $10 \mathrm{~m}$ da chaminé da caldeira, bem como os dados da literatura/legislação, estão demonstrados na Tabela 3.

Tabela 3 - Concentração de poluentes a 10m da base da chaminé da caldeira

\begin{tabular}{|c|c|c|c|}
\hline $\begin{array}{l}\text { Elementos } \\
\text { analisados }\end{array}$ & Gás natural & Óleo combustível ${ }^{\mathrm{a}}$ & Literatura/Legislação \\
\hline $\mathrm{CO}(\mathrm{ppm})$ & 0,1 & - & $0,12^{\mathrm{b}} ; 0,1^{\mathrm{c}} ; 9^{\mathrm{d}}(8 \mathrm{~h}), 35^{\mathrm{d}}(1 \mathrm{~h}) ; 9^{\mathrm{f}}(8 \mathrm{~h}), 35^{\mathrm{f}}(1 \mathrm{~h}) ; 0-9,0^{\mathrm{g}}$ \\
\hline $\mathrm{NO}(\mathrm{ppm})$ & 0,0 & 1,2 & $0,00001-0,00005^{\mathrm{b}} ;<0,002^{\mathrm{c}}$ \\
\hline NO2 (ppm) & 0,0 & - & $0,0001-0,0005^{\mathrm{b}} ;<0,002^{\mathrm{c}} ; 0,053^{\mathrm{d}}(\mathrm{maa})^{*} ; 0,2^{\mathrm{f}} ; 0-0,2^{\mathrm{g}}$. \\
\hline NOx (ppm) & 0,0 & - & $154^{\mathrm{e}}$ (gás); $156^{\mathrm{h}}$ (gás); $370^{\mathrm{e}}$ (óleo); $779^{\mathrm{h}}$ (óleo). \\
\hline
\end{tabular}

Obs: 1) A emissão de CO2 e o ponto de orvalho não foram detectados pelo Analisador Testo 350 XL;

2) * Média aritmética anual.

Fonte: ${ }^{\mathrm{a}}$ Okano (2004); ${ }^{\mathrm{b}}$ Lora \& Teixeira (2001); ${ }^{\mathrm{c}}$ Mota (2000); ${ }^{\mathrm{d}}$ USEPA (2010); ${ }^{\mathrm{e}}$ World Bank (1998); Res. CONAMA n. 003/90; ${ }^{\mathrm{g}}$ CETESB (2010); ${ }^{\mathrm{h}}$ Res. CONAMA n. 382/06.

A média da concentração obtida neste estudo para $\mathrm{CO}, \mathrm{NO}, \mathrm{NO}_{2}$ e $\mathrm{NO}_{x}$ classifica o ar como limpo em todas as legislações vigentes.

Analisando a Tabela 3, verificou-se uma diminuição na concentração de NO com a transformação da caldeira para operar com combustão a gás natural, cuja média passou de 1,2 ppm para 0,0 ppm.

É importante frisar que, em que pese à média da concentração de CO apresentada por Okano (2004), no interior da chaminé, estar acima da fixada pelas legislações vigentes, em quatorze das 30 medidas realizadas em seu estudo, a concentração ficou abaixo do limite estabelecido pela Resolução CONAMA n. 003/90 e USEPA (2010), ou seja, menor que 35 ppm. O mesmo ocorreu em relação à concentração de NO2 que, em apenas oito das trinta medidas realizadas, ultrapassou o limite estabelecido pela Resolução CONAMA n. 003/90, que é de 0,2 ppm, tendo, inclusive, sido nulas 21 medidas, isto é, de valor igual a 0,0 ppm.

\section{Conclusões e recomendações}

A utilização de gás natural como combustível para combustão da caldeira proporcionou melhor rendimento energético, gerando uma minimização dos resíduos e melhoria no padrão da qualidade do ar, sendo que as concentrações de poluentes emitidas atendem plenamente às legislações pertinentes.

A principal razão para a baixa contribuição da caldeira, em termos de concentração de poluentes emitidos, foi a mudança para combustível mais limpo, com baixo teor de enxofre e cinzas, como a troca do óleo combustível BPF 2A pelo gás natural considerado uma fonte de energia segura, eficiente e econômica.

Este estudo revelou uma minimização da agressão ao meio ambiente e uma diminuição dos custos operacionais, evitando gastos com manutenção, estocagem, limpeza e com a compra de equipamentos antipoluição, como 
filtros e lavadores de gás. O abastecimento contínuo evita movimentação e transferência entre reservatórios com diferentes temperaturas no preparo para queima, como ocorre com o óleo combustível.

Analisando o resultado do investimento (conversão da caldeira e aquisição de combustível), constatou-se que o NHU tomou uma decisão acertada ao optar pela conversão da caldeira para gás natural.

A troca proporcionou, ainda, maior higiene na casa de caldeiras, pela eliminação dos resíduos e vazamentos de óleo, liberando gases de exaustão mais limpos, uma vez que a geração de energia dá-se de forma mais econômica e limpa em relação a outros combustíveis. Os materiais particulados e fuligem deixaram de ser lançados para a atmosfera, melhorando as condições do ar no NHU e áreas circunvizinhas, evitando multas e advertências de órgãos ambientais, bem como reclamações dos moradores da região, e contribuindo para o desenvolvimento local.

Com a identificação dos gases emitidos, feitas as análises e comparações, e verificada a melhoria das condições atmosféricas e as vantagens advindas do uso do gás natural (econômicas, ambientais, operacionais, técnicas e de qualidade), o resultado deste estudo poderá gerar confiança e credibilidade, aumentando a adesão de empresas à novidade, criando alternativas menos impactantes para o meio ambiente e contribuindo para a diminuição do aquecimento global e para a destruição da camada de ozônio.

O estudo dos poluentes atmosféricos emitidos por uma caldeira flamotubular a gás natural não foi esgotado com a apresentação deste trabalho, mas, certamente, poderá contribuir como objeto de novos estudos e de outros projetos de pesquisa relacionados a emissões de gases poluentes oriundos de geradores de energia a combustíveis fósseis.

É válido dizer que a demanda por geração de energia é crescente. Gerar energia suficiente para atender aos diversos usos, com diminuição da agressão ao meio ambiente, é o grande desafio da humanidade.

A solução passa pela conscientização e educação do consumidor e pelo desenvolvimento de tecnologias que levem ao aumento da eficiência energética de equipamentos, sistemas e processos. Para melhor rendimento da caldeira e maior controle da concentração dos poluentes emitidos, deve ser adotado um sistema de controle efetivo da combustão.

Todas as ocorrências que influem nas condições de segurança da caldeira, bem como informações sobre inspeções periódicas e extraordinárias, devem ser permanentemente atualizadas no livro de ocorrências, sendo disponibilizadas para consultas.

É de extrema importância o acompanhamento da qualidade da água que é utilizada na caldeira, pois a presença de sais de cálcio leva ao depósito de carbonato de cálcio nas paredes externas dos tubos de fogo, o que diminui a eficiência (prejudica a troca de calor) gerando, inclusive, aumento no consumo de combustível e enfraquecimento desses tubos.

Deve-se, portanto, proporcionar reciclagem permanente aos operadores da caldeira, de forma a repassar informações sobre as condições físicas e operacionais dos equipamentos e medidas de segurança, com vistas a uniformizar procedimentos e, também aplicar modelos matemáticos a fim de identificar a que distância da caldeira ocorre impacto ambiental, devido à emissão dos poluentes gasosos.

\section{Referências}

AGÊNCIA DE PROTEÇÃO AMBIENTAL DOS ESTADOS UNIDOS (USEPA). In: COMPANHIA DE TECNOLOGIA DE SANEAMENTO AMBIENTAL (CETESB). Relatório de qualidade do ar no Estado de São Paulo. São Paulo, 2010. 237 p. Disponível em: <http://www. cetesb.sp.gov.br/ar/qualidade-do-ar/31-publicacoese-relatorios>. Acesso em: 30 ago. 2011.

ARRUDA, J. J. A. História moderna e contemporânea. 8. ed. São Paulo: Ática, 1977. p. 119-135.

BERMANN, C. A perspectiva da sociedade brasileira sobre a definição e implementação de uma política energética sustentável - uma avaliação da política oficial. In: SEMINÁRIO INTERNACIONAL DE FONTES ALTERNATIVAS DE ENERGIA E EFICIÊNCIA ENERGÉTICA: OPÇÃO PARA UMA POLÍTICA ENERGÉTICA SUSTENTÁVEL NO BRASIL, 2002. Anais... Brasília, DF: Câmara dos Deputados, 2002. 13 p. Disponível em: <http:/ / www.riosvivos.org.br/arquivos/571566216. pdf>. Acesso em: 31 jan. 2005.

BRASIL. Resolução CONAMA n. 005, de 15/6/1989. Institui o Programa Nacional de Controle da Poluição do Ar (PRONAR). Publicada no DOU de 30/8/1989. In: CONSELHO NACIONAL DO MEIO AMBIENTE. Resoluções CONAMA: 1984/91. 4. ed. rev. e aum. Brasília: IBAMA, 1992. p. 161-165.

Resolução CONAMA n. 003, de 28/6/1990. Estabelece os padrões nacionais de qualidade do ar. Publicada no DOU de 22/8/1990. In: CONSELHO NACIONAL DO MEIO AMBIENTE. Resoluções CONAMA: 
1984/91. 4. ed. rev. e aum. Brasília: IBAMA, 1992. p. 199-205.

Resolução CONAMA n. 382, de 26/12/2006. Estabelece os limites máximos de emissão de poluentes atmosféricos para fontes fixas. Publicada no DOU de 2/1/2007. Disponível em: <http://www.mma.gov. $\mathrm{br} /$ port/conama/res/res06/res38206.pdf>. Acesso em: 30 ago. 2011.

COMPANHIA DE TECNOLOGIA DE SANEAMENTO AMBIENTAL (CETESB). Relatório de qualidade do ar no Estado de São Paulo. São Paulo, 2010. Disponível em: <http://www.cetesb.sp.gov.br/ar/qualidade-do-ar/31publicacoes-e-relatorios>. Acesso em: 30 ago. 2011.

LORA, E. S; TEIXEIRA, F. N. Energia e meio ambiente.
In: MARQUES, M.; HADDAD, J.; MARTINS, A. R. S. (Coord.). Conservação de energia: eficiência energética de instalações e equipamentos. Itajubá, MG: FUPA, 2001. p. 30-89. (cap. 2).

MOTA, S. Introdução à engenharia ambiental. 2. ed. Rio de Janeiro: ABES, 2000.

OKANO, S. M. Avaliação dos poluentes atmosféricos e ruídos emitidos por uma caldeira flamotubular a óleo combustível BPF 2A. 2004. 101 p. Dissertação (Mestrado em Tecnologias Ambientais) - Universidade Federal de Mato Grosso do Sul, Centro de Ciências Exatas e Tecnologia, Campo Grande, MS, 2004.

TORREIRA, R. P. Geradores de vapor. São Paulo: Companhia de Melhoramentos, 1995. p. 131-230 e p. 361-387. 
